Saudi Journal of Oral and Dental Research

Abbreviated Key Title: Saudi J Oral Dent Res

ISSN 2518-1300 (Print) |ISSN 2518-1297 (Online)

Scholars Middle East Publishers, Dubai, United Arab Emirates

Journal homepage: https://saudijournals.com/sjodr

\title{
Evaluation of Different Non Rigid Fixation Techniques in Dentoalveolar Fracture: A Comparative Study
}

\author{
Dr. Rahul VC Tiwari, OMFS, FOGS, PhD Scholar ${ }^{*}$, Dr. Aliza Rizvi, PG student ${ }^{2}$, Dr. Sumaiyya Patel, MDS ${ }^{3}$, Dr. \\ Shruthi Sukumar, BDS, ${ }^{4}$, Dr. Geetanjali Singh, MDS ${ }^{5}$, Dr. Heena Tiwari, BDS, PGDHHM ${ }^{6}$ \\ ${ }^{1}$ Dept of OMFS, Narsinbhai Patel Dental College and Hospital, Sankalchand Patel University, Visnagar, Gujarat \\ ${ }^{2}$ Dept of OMFS, Maharishi markandeshwar University of dental sciences n research, Mullana \\ ${ }^{3}$ Assistant professor, Dept of oral and maxillofacial surgery, Shri Yashwant Roa Chawan Dental College and Hospital, Ahamednagar, Maharashtra \\ ${ }^{4}$ Kamineni Institute of Dental Sciences, Narketpalli, Telangana, India \\ ${ }^{5}$ Senior lecturer, Department of Prosthodontics including Crown, Bridge and Implantology, Himachal Dental College Sundernager Distt- Mandi (H.P) \\ ${ }^{6}$ Ex-Government Dental Surgeon, Kondagaon, Chhattisgarh, India
}

DOI: $10.36348 /$ sjodr.2020.v05i09.014

| Received: 09.08.2020 | Accepted: 20.09.2020 | Published: 24.09.2020

*Corresponding author: Dr. Rahul VC Tiwari

Abstract

Introduction: Dentalalveolar fractures are commonly encountered in emergency settings and dental clinics. In adult patients they can occur due to different reasons and may be accompanied by various other facial injuries. Early stabilization and fixation are necessary for treatment if such injuries. Objective: To compare the efficiency of different non rigid fixation techniques in the treatment of dentoalveolar fractures. Materials $\&$ Methods: This comparative study was carried out on 87 patients belonging to young, middle, and old age groups. The causes of these fractures were also noted. One of eight different non rigid fixation modalities namely Direct Interdental wiring, Indirect Eyelet Interdental wiring, Indirect IVY Loop Interdental wiring, Continuous Multiple Loop Wiring, Erich's Arch Bars, Cap Splints, Gunning Splints and Pin Fixation were used for treatment in each case and complications occurring after three weeks in each treatment group were observed and compared among the groups. Results: 87 adults took part in our study. $49 \%$ of all the fractures were due to Road Traffic Accidents (RTA) and 25\% were due to assault. 37 were treated with Erich's Arch Bars, 14 with Direct Interdental wiring, 11 with Indirect Eyelet Interdental wiring, 10 with Indirect IVY Loop Interdental wiring, 6 with Continuous Multiple Loop Wiring, 4 with Cap Splints, 3 with Pin Fixation and 2 with Gunning Splints. All treatment methods had high success rates (normal union), which ranged from 70- 100\%. Conclusion: Non rigid fixation techniques are viable methods of treatment in dentoalveolar fractures.

Keywords: Dentoalveolar fracture, Non rigid fixation, Dental wiring, Arch bar, Cap splint, Gunning splint.

Copyright @ 2020: This is an open-access article distributed under the terms of the Creative Commons Attribution license which permits unrestricted use, distribution, and reproduction in any medium for non-commercial use (NonCommercial, or CC-BY-NC) provided the original author and source are credited.

\section{INTRODUCTION}

Maxillary and mandibular fractures often involve the teeth in dentate patients. Fracture sites depend upon the mechanism of injury, magnitude and direction of impact force, prominence of mandible and anatomy of site [1]. The common causes of dentolaveolar fractures range from assault, road traffic accidents, falls and other factors like interpersonal violence and sports injuries [2]. In the past, all fractures involving the face and jaw bones including that involving the teeth were treated with closed reduction and internal fixation techniques like miniplatesand lagscrews. Now, with advances in the field of Oral and Maxillofacial surgery, treatment using non rigid fixation techniques like Intermaxillary fixation with different dental wiring techniques are being increasingly used [3-5]. Many studies are available in the dental literature that compares a few rigid fixation techniques in the treatment of dentoalveolar fractures with non-rigid fixation, but there are scarcely any studies comparing different non rigid fixation fixation techniques. Thus, the current study was done to compare the efficiency of different non rigid fixation techniques in the treatment of dentoalveolar fractures.

\section{MATERIALS \& METHODS}

This comparative study was carried out on 87 patients belonging to young, middle, and old age groups. All study participants gave consent to take part in the study. All the study participants were diagnosed with one of the following five types of dentoalveolar fractures as per location, i.e. Maxillary anterior, Maxillary posterior, Mandibular anterior, Mandibular posterior and $\mathrm{Bi}$ jaw anterior. The causes of these 
fractures were also noted. One of eight different non rigid fixation modalities namely Direct Interdental wiring, Indirect Eyelet Interdental wiring, Indirect IVY Loop Interdental wiring, Continuous Multiple Loop Wiring, Erich's Arch Bars, Cap Splints, Gunning Splints and Pin Fixation were used for treatment in each case and complications occurring after three weeks in each treatment group were observed and compared among the groups. Data were compiled and descriptive statistics were used for analysis of the data.

\section{RESULTS}

87 patients took part in the study, out of which 65 were males and 21 were females. The participants belonged to one of the following three age groups: Young (18 to 30 years), middle ( 31 to 50 years) and old (51 to 70 years). Table 1 shows the distribution of the study participants as per their gender and age group.
The causes of the dentoalveolar fractures in the study participants were also noted as displayed in Table 2. $49 \%$ of all the fractures were due to Road Traffic Accidents (RTA). All the study participants were diagnosed with one of the following five types of dentoalveolar fractures as per location, i.e. Maxillary anterior, Maxillary posterior, Mandibular anterior, Mandibular posterior and $\mathrm{Bi}$ jaw anterior. Table 3 shows the distribution of the study population according to the fracture site. One of eight different non rigid fixation modalities namely Direct Interdental wiring, Indirect Eyelet Interdental wiring, Indirect IVY Loop Interdental wiring, Continuous Multiple Loop Wiring, Erich's Arch Bars, Cap Splints, Gunning Splints and Pin Fixation were used for treatment in each case. Complications occurring after three weeks in each treatment group were observed and compared among the groups as shown in Table 4.

Table-1: Age and gender distribution of the study population

\begin{tabular}{|l|l|l|l|}
\hline AGE & GENDER & TOTAL \\
\hline & MALE & FEMALE & \\
\hline YOUNG (18 TO 30) & 23 & 6 & 29 \\
\hline MIDDLE (31 TO 50) & 29 & 12 & 41 \\
\hline OLD (51 TO 70) & 14 & 3 & 17 \\
\hline TOTAL & 65 & 21 & 87 \\
\hline
\end{tabular}

Table-2: Distribution of cause of fracture among the study population

\begin{tabular}{|l|l|l|}
\hline CAUSE & NUMBER & PERCENT \\
\hline ASSAULT & 21 & 25 \\
\hline RTA & 43 & 49 \\
\hline SELF FALL & 13 & 15 \\
\hline OTHERS & 10 & 11 \\
\hline
\end{tabular}

Table-3: Types of Dentoalveolar Fractures

\begin{tabular}{|l|l|}
\hline Type & Number \\
\hline Maxillary Anterior & 28 \\
\hline Maxillary Posterior & 13 \\
\hline Mandibular Anterior & 22 \\
\hline Mandibular Posterior & 01 \\
\hline Bi Jaw Anterior & 23 \\
\hline
\end{tabular}

Table-4: Distribution of type of complications observed after 3 weeks according to type of fixation among the study population

\begin{tabular}{|l|l|l|l|l|l|l|}
\hline Type of fixation & Number & Infection & Malocclusion & Malunion & $\begin{array}{l}\text { Normal } \\
\text { Union (n) }\end{array}$ & $\begin{array}{l}\text { Normal } \\
\text { Union \% }\end{array}$ \\
\hline Direct Interdental wiring & 14 & 1 & 2 & 1 & 13 & $92.86 \%$ \\
\hline $\begin{array}{l}\text { Indirect Eyelet } \\
\text { Interdental wiring }\end{array}$ & 11 & 0 & 2 & 2 & 9 & $81.81 \%$ \\
\hline $\begin{array}{l}\text { Indirect IVY Loop } \\
\text { Interdental wiring }\end{array}$ & 10 & 0 & 3 & 1 & 9 & $90.00 \%$ \\
\hline $\begin{array}{l}\text { Continuous Multiple } \\
\text { Loop Wiring }\end{array}$ & 6 & 1 & 0 & 1 & 5 & $83.33 \%$ \\
\hline Erich's Arch Bars & 37 & 6 & 1 & 11 & 26 & $70.27 \%$ \\
\hline Cap Splints & 4 & 0 & 0 & 0 & 4 & $100 \%$ \\
\hline Gunning Splints & 2 & 0 & 0 & 0 & 2 & $100 \%$ \\
\hline Pin Fixation & 3 & 0 & 1 & 0 & 3 & $100 \%$ \\
\hline
\end{tabular}




\section{DISCUSSION}

Dentalalveolar fractures are commonly encountered in emergency settings and dental clinics. In adult patients they can occur due to different reasons and may be accompanied by various other facial injuries. The common causes of dentoalveolar fractures in adults are assaults, road traffic accidents, falls and other reasons like contact sports, industrial accidents etc. [6]. The causes of dentoalveolar fractures in our study population were identified. It was found that $49 \%$ of these fractures were a result of Road Traffic Accidents. Our results are in agreement with that of Khan MS et al. [7] Also, Rezende FM et al.[8] have reported that the average age of those who encounter dentoalveolar fractures due to road traffic accidents is 27.7 years. Among our study participants 28 were diagnosed with fracture in Maxillary anterior region, 13 in Maxillary posterior region, 22 in Mandibular anterior region,1in Mandibular posterior and 23 had Bi jaw anterior region fractures. The participants in our study were treated with different types of non-rigid fixation methods. Out of the 87 study participants the highest, i.e. 37 were treated with Erich's Arch Bars, 14 with Direct Interdental wiring, 11 with Indirect Eyelet Interdental wiring, 10 with Indirect IVY Loop Interdental wiring, 6 with Continuous Multiple Loop Wiring, 4 with Cap Splints, 3 with Pin Fixation and 2 with Gunning Splints. On follow-up with the study participants after 3 weeks, it was found that all treatment methods had high success rates (normal union), which ranged from 70- 100\%. The common complications that had risen were infection, malocclusion and malunion. Khan MS et al. [7] and Khan A et al. [9] have also reported similar complication in their study on mandibular angle fractures. Maloney K [6] has also advocated the use of circummandibular wires in case of dentoalveolar fractures. Also, Khan a et al. [9] have reported lower infection rates with non-rigid fixation as compared with rigid fixation. They also compared complications that occurred in patients treated with rigid and non-rigid fixation and found no statistically significant difference between the two groups.

\section{CONCLUSION}

Non rigid fixation techniques are viable methods of treatment in dentoalveolar fractures and do not seem to be associated with complications in majority of cases.

\section{ACKNOWLEDGMENT}

We thank Dr. Rashmi Kolichala BDS, MPA, Sri Venkata Sai Institute of Dental Sciences,Telangana, India for assisting in literature collection and reviewing the manuscript.

\section{REFERENCES}

1. Mwaniki, D. L., \& Guthua, S. W. (1990). Occurrence and characteristics of mandibular fractures in Nairobi, Kenya. British journal of oral and maxillofacial surgery, 28(3), 200-202.

2. Telfer, M. R., Jones, G. M., \& Shepherd, J. P. (1991). Trends in the aetiology of maxillofacial fractures in the United Kingdom (19771987). British journal of oral and maxillofacial surgery, 29(4), 250-255.

3. Peled, M., Laufer, D., Helman, J., \& Gutman, D. (1989). Treatment of mandibular fractures by means of compression osteosynthesis. Journal of oral and maxillofacial surgery, 47(6), 566-569.

4. Jaques, B., Richter, M., \& Arza, A. (1997). Treatment of mandibular fractures with rigid osteosynthesis: using the AO system. Journal of oral and maxillofacial surgery, 55(12), 1402-1406.

5. Shetty, V., Atchison, K., Leathers, R., Black, E., Zigler, C., \& Belin, T. R. (2008). Do the benefits of rigid internal fixation of mandible fractures justify the added costs? Results from a randomized controlled trial. Journal of Oral and Maxillofacial Surgery, 66(11), 2203-2212.

6. Maloney, K. (2015). Circummandibular wires for treatment of dentoalveolar fractures adjacent to edentulous areas: a report of two cases. Craniomaxillofacial trauma \& reconstruction, 8(3), 246-250.

7. Khan, M. S., Siddiqui, S. U., Iqbal, N., \& Kashif, S. (2019, December). Comparison between Rigid Fixation and Semi Rigid Fixation of Mandibular Angle Fracture. In Med. Forum, 30(12): 36.

8. Do Carmo Rezende, F. M., Gaujac, C., Rocha, A. C., \& de Melo Peres, M. P. S. (2007). A prospective study of dentoalveolar trauma at the Hospital das Clínicas, São Paulo University Medical School. Clinics, 62(2), 133-138.

9. Khan, A., Khitab, U., \& Khan, M. T. (2010). A comparative analysis of rigid and non-rigid fixation in mandibular fractures: A prospective study. Pakistan Oral \& Dental Journal, 30(1). 